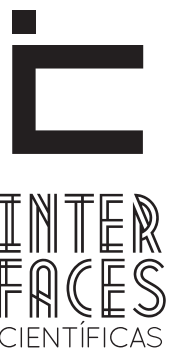

EDUCAÇÃO

ISSN IMPRESSO 2316-333X

ISSN ELETRÔNICO 2316-3828

Dossiê

\title{
UM DEBATE ACERCA DA ORIGEM DA GEOGRAFIA ESCOLAR NO BRASIL
}

Maria Adailza Martins de Albuquerque ${ }^{1}$

\section{RESUMO}

Este trabalho tem como objetivo discutir a origem da Geografia escolar brasileira, buscando reconfigurar o papel das províncias neste processo e nos contrapor a posição de autores que estabeleceram como marco de origem dessa disciplina a fundação do Colégio Pedro II. Para dar continuidade a pesquisa que pretendemos construir para fundamentar a nossa posição discutiremos a possibilidade de criação de uma rede de pesquisadores para traba-
Lhar com temáticas relativas à Geografia escolar, na busca de compreender a contribuição das províncias do Nordeste na constituição histórica dessa disciplina no século XIX.

\section{PALAVRAS-CHAVE}

Origem da Geografia Escolar. Fonte Histórica. Rede de Pesquisa. 


\section{ABSTRACT}

This paper aims to discuss the origin of the schooling Geography in Brazil, trying to reconfigure the role of the provinces in this process and to contrast the position of authors who have established as the origin of this discipline the founding of Pedro II School. To continue the research that we plan now and to build to support our position we will discuss the possibility of creating a network of researchers to work with themes related to school Geography, seeking to understand the contribution of the northeastern provinces in the historical development of this discipline in the nineteenth century.

\section{KEYWORDS}

The origin of schooling Geography. Historical Source. Net Research.

\section{UM DEBATE NECESSÁRIO: A ORIGEM DA GEOGRAFIA ESCOLAR NO BRASIL}

Há algum tempo se tem estabelecido que a origem da Geografia escolar brasileira se deu com a fundação do Colégio Pedro II, em 1837, na cidade do Rio de Janeiro (ROCHA, 1996). Entretanto, em publicações recentes temos discutido a definição dessa data como um marco histórico único que estabelece a origem dessa disciplina. A nossa proposição não tem sido questionar a data em que se estabeleceu a institucionalização dessa disciplina para o ensino secundário no referido Colégio - com um currículo que trazia valores europeus de civilização e progresso, um modelo francês de educação, organização das disciplinas de humanidades, entre outras características - mas sim, trazer para o debate alguns ques-

\section{RESUMEN}

Este trabajo tiene como objetivo discutir el origen de la escuela Brasileño de Geografía, tratando de reconfigurar el papel de las provincias en este proceso y para contrastar en la posición de los autores que se han establecido como el origen de esta disciplina de la fundación de Colégio Pedro II. Para continuar la investigación que tenemos previsto construir para apoyar nuestra posición vamos a discutir la posibilidad de crear una red de investigadores para trabajar temas relacionados con la Geografía escolar, buscando entender la contribución de las provincias del noreste en el desarrollo histórico de esta disciplina en el siglo XIX.

\section{PALABRAS CLAVE}

Origen de la Geografía Escolar. Las Fuentes Históricas. Red de Investigación. tionamentos importantes que tem como eixo central um ponto de vista teórico. Assim, algumas questões se evidenciam: 1 discutir a centralização do olhar sobre história da educação brasileira, especialmente o enfoque que se destina a Geografia escolar, ou seja, é preciso contar essa historia a partir de outros lugares e não somente pensá-la a partir do centro, ou seja, do Município da Corte, como era conhecida a cidade do Rio de Janeiro, no Império; 2 - Atentar para um debate sobre fontes históricas, tão necessário à pesquisa sobre a disciplina escolar e 3 - Discutir o que pensamos sobre a atuação do Colégio Pedro II, dos cursos preparatórios, dos liceus fundados nas províncias do país, em um período em que não havia 
efetivamente um sistema nacional de ensino e que os conflitos entre as províncias e o poder central era uma realidade latente.

A ideia de uma história contada a partir da periferia não corresponde aqui a perspectiva da História vista de baixo (SHARPE, 1992), pois não é este o nosso propósito. Apesar de querermos dar voz e trabalhar com documentação pouco consultada, quando se busca compreender a história dessa disciplina, não trabalharemos aquela perspectiva teórica, de "os de baixo", visto que a documentação com a qual trabalhamos também era fruto das relações de dominação, também foram implementadas pelo Estado e, portanto, representava o interesse de uma classe dominante na época e não das classes subalternas. Entretanto, é importante ressaltar que essa classe dominante tinha interesses que muitas vezes conflitavam com o poder central, de forma que é preciso conhecer melhor essa relação e como ela pode ter afetado ou não a educação nas províncias e quais as contribuições dadas pelas províncias para a História da Educação brasileira e, mais especificamente, aquelas que foram dadas pela Geografia escolar.

Outra questão diz respeito a alguns debates que a História vem fazendo há algum tempo e que precisamos nos aproximar dele, tendo em vista, que recorremos a essa área do conhecimento para conseguimos compreender historicamente o papel da Geografia escolar. Dai a necessidade de nos aproximarmos de um debate feito desde a Escola dos Annales e vem tomando novos rumos com as contribuições da História cultural. Assim, alguns questionamentos orientarão esse texto: Que percurso temos feitos como historiadores de uma disciplina escolar? Como temos escrito essa história? Como temos lidado com as fontes? Como temos lidado com o tempo histórico? Visando trazer este debate recorreremos ao nosso percurso como pesquisadora e as dificuldades encontradas. Assim, aproveitaremos para fazer um balanço dos últimos sete anos a que temos nos dedicado a pesquisa sobre Geografia escolar na UFPB.
Desse modo, este texto se propõe a trazer a baila um debate que temos feito no Grupo de Pesquisa Ciência, Educação e Sociedade - GPCES na Universidade Federal da Paraíba - UFPB, especialmente com os nossos orientandos de graduação e pós-graduação; com professores da rede pública que participam dos grupos de estudos; com nossos alunos das disciplinas Prática de Ensino de Geografia, no Curso de Geografia e Metodologia do Ensino de Geografia, no Curso de Pedagogia e as disciplinas ofertadas nos Programas de Pós-Graduação em Geografia e em Educação. Assim, temos feito um grande esforço na busca de construir uma perspectiva teórica que nos possibilite contar uma história da Geografia escolar a partir de um enfoque da periferia, ou seja, a partir das descobertas que temos feito nas nossas pesquisas, levando em consideração os debates que a própria História, e em especial, a História da Educação tem feito nos últimos anos.

Já é conhecido que trabalhamos em uma perspectiva da história das disciplinas escolares a partir de autores como Chervel (1990) e Goodson (1990) e que esse referencial nos possibilita compreender a escola como espaço de produção do conhecimento escolar (ALBUQUERQUE, 2010; 2011; 2011a). Além disso, partimos do pressuposto de que as disciplinas escolares apresentam certa autonomia e, por isto, não podem ser vistas como simples reprodução do conhecimento acadêmico ou mesmo como uma simplificação desse. Desse modo, para compreender o papel das disciplinas escolares é necessário conhecer o seu percurso histórico e é nesta perspectiva que hoje desenvolvemos o nosso trabalho na UFPB. Assim, desde que chegamos aqui, em 2005, o nosso esforço tem sido o de conhecer as contribuições da Geografia escolar nordestina na constituição da Geografia escolar brasileira.

Com este intuito conseguimos aprovar projetos em editais, formar grupos de estudos, envolvermos em pesquisas alunos da graduação, da pós-gradua- 
ção e professores da rede pública da Paraíba e de outros estados nordestinos, como Ceará, Pernambuco e Rio Grande do Norte. Estamos montando um acervo virtual com a localização de livros didáticos de Geografia que se encontram em bibliotecas da Paraíba e Pernambuco; esse também contará com o catálogo elaborado com obras didáticas de Geografia que se encontram espalhadas nas bibliotecas dos Institutos Históricos e Geográficos de todos os Estados do Nordeste, este último projeto, feito com apoio institucional do CNPq, a partir do edital universal - Educação. Esse acervo virtual possibilitará aos pesquisadores em geral fazerem buscas e evitar viagens dispendiosas a procura de fontes de pesquisas, muitas vezes raras. Ainda com este intuito montamos uma biblioteca do livro didático que conta com obras de todas as disciplinas escolares, no GPCES. Essa tem recebido acervo a partir de doações, como também temos comprado obras. Neste momento estamos organizando uma rede de pesquisa que contará com alunos e professores de vários estados nordestinos e que tocará projetos mais articulados entre as instituições de pesquisa dessa região. Diante de um quadro nacional que pouco tem valorizado a pesquisa na área de ensino de Geografia, acreditamos que o nosso esforço não tem sido em vão, o que nos anima a ponto de recebermos o próximo Encontro Nacional de Prática de Ensino de Geografia - ENPEG na nossa instituição no ano de 2013.

Ainda queremos esclarecer que os recursos que temos recebido para pesquisas sobre Geografia escolar, em geral, são oriundos do comitê de Educação e não do de Geografia no CNPq. Isto é dito aqui em forma de desabafo, visto que formamos o maior número de profissionais para trabalharem como docentes das escolas brasileiras, entretanto, não temos no Comitê de Geografia do CNPq nem um espaço onde colocarmos as nossas pesquisas, é como se não existíssemos ou como se a Geografia escolar não necessitasse de pesquisa. Fosse um acessório para a produção acadêmica.

\section{GEOGRAFIA[S] ESCOLAR[ES] NO SÉCULO XIX: CONHECEMOS OS CONTEÚDOS TRABALHADOS?}

No X Encontro Cearense de História da Educação e III Encontro Cearense de Geografia Escolar - Cultura, Educação, Espaço e Tempo, realizado na Universidade Estadual do Ceará, no ano de 2011, fomos provocadas, mesmo sem a nossa presença, sobre o fato de termos, em diversos momentos questionado o marco histórico de origem da Geografia escolar no Brasil, em 1837, com a fundação do Colégio Pedro II e afirmarmos que a Geografia tem origem anterior a esta data e que poderia ter origem na Paraíba. 0 argumento estabelecido para negar a nossa hipótese era que fazíamos tal afirmação nos baseando apenas em relatórios de províncias.

Isto não foi nenhuma novidade para nós, pois o marco de origem estabelecido a partir da fundação do Colégio Pedro II já tem se tornado quase que uma tese aceita por todos que estudam a Geografia escolar, de modo que questioná-lo é como se estivéssemos quebrando um marco pronto e acabado. Sobre a provocação feita queremos apontar para alguns pontos que justificam o nosso posicionamento: primeiramente, é importante discutir com que ideia de educação trabalhamos para falar de um período quando a escola não tinha as mesmas características das atuais; o segundo, refere-se a questão das fontes históricas, será que vamos contar a história da Geografia escolar nos baseando somente nos documentos "oficiais" e autorizados? E, por último, vamos discutir essa origem tendo como referência somente o centro geográfico do poder imperial brasileiro? Estes questionamentos orientarão este trabalho.

Gondra e Schueler (2008), ao fazer uma síntese sobre a história da educação brasileira nos oitocentos, advertem que a noção de educação a que se recorre geralmente nesse campo do conhecimento tende a compreendê-la somente a partir das ações institucionais mesmo quando outras formas, não ins- 
titucionalizadas de educação, também compunham esse processo. Além disso, ressaltam os autores

\begin{abstract}
"[...] a heterogeneidade das forças educativas e iniciativas específicas que elas organizam no vasto território que se pretende unificar, sendo esta uma das funções atribuídas à educação que passa a se processar nas escolas. Com isto também vale chamar a atenção para as iniciativas criadas, pelo aparelho do Estado, pelas Igrejas, empresários, filantropos e agentes da intelectualidade como médicos, juristas e militares, por exemplo. (p. 11).
\end{abstract}

A partir desta afirmação podemos aferir que a escola aparece no Brasil com formas distintas e que mesmo assim, cumpriam o papel de educar parte da população brasileira. Não podemos marcar a história da Geografia escolar somente por aquilo que foi estabelecido como uma "escola modelo", com um currículo organizado em disciplinas das humanidades, com sequência de séries ou anos, com adoção de livros didáticos e atlas geográficos. Pois outra(s) geografia(s) escolare(s) já haviam sido trabalhadas, inclusive a partir da relação professor aluno. Ou será que iremos definir como escola somente o modelo que hoje entendemos como tal, ou seja, uma instituição organizada a partir das características supracitadas? Isto seria mesmo anacronismo, pois a escola, ao longo de sua história se configurou de diferentes maneiras.

O modelo de Cadeiras Isoladas (PINHEIRO, 2002), não pode ser compreendida como escola? As instituições privadas que foram criadas especialmente para oferecer cursos preparatórios, também não podem ser consideradas escolas? Será que somente podemos nos espelhar no modelo de escola que temos hoje? disso que estamos falando.

A Geografia foi efetivamente uma cadeira isolada criada na cidade da Paraíba, no ano de 1831, conforme se pode comprovar na legislação a seguir, portanto cinco anos antes da criação do Colégio Pedro II. Não considerar este dado para pensarmos a história dessa disciplina é querer negar deliberadamente o papel das províncias nesse processo. E se é necessário um documento oficial para comprovar a criação dessa cadeira ele existe, como se pode observar a seguir:

\section{Legislação Informatizada - Decreto de 7 de Junho de 1831 - Publicação Original \\ Decreto de 7 de Junho de 1831}

Crêa diversas cadeiras de instrucção secundaria na cidade da Parahyba.

A Regencia Provisoria, em Nome do Imperador o Senhor D. Pedro II, Tem Sanccionado, e Manda que se execute a Resolução seguinte da Assemblea Geral:

Art $1^{\circ}$ Haverão na cidade da Parahyba uma cadeira de rhetorica, geographia, e elementos de historia, outra de philosophia racional, e moral, e outra de francez.

Art $2^{\circ} 0$ Presidente da respectiva Provincia, em Conselho, proverá as sobreditas cadeiras, e txará interinamente os ordenados dos Professores, guardando acerca de uma outra cousa o disposto nos arts $3^{\circ}, 7^{\circ}$, e $8^{\circ}$, da Lei de 15 de Outubro de 1827, que creou as escolas de primeiras letras.

Art $3^{\circ}$ Ficam revogadas todas as disposições em contrario.

Manoel José de Souza França, do Conselho do mesmo Imperador, Ministro e Secretario de Estado dos NEgocios da Justiça, encarregado interinamente dos do Imperio, o tenha assim entendido, e faça executar.

Palacio do Rio de Janeiro, em sete de Junho de mil oitocentos trinta e um, decimo da Independencia e do Imperio.

MARQUEZ DE CARAVELLAS.

NICOLAO PEREIRA DE CAMPOS VERGUEIRO

FRANCISCO DE LIMA E SILVA

Manoel José de Souza França.

(Coleção de Leis do Império do Brasil - 1831, Página 8 Vol. 1. Rio de Janeiro, 1875)

Outra questão deve ser ressaltada, neste mesmo período outras províncias, localizadas no atual Nordeste, também criaram cadeiras isoladas de Geografia: um ano antes na província de Pernambuco, na cidade de Olinda; no mesmo ano na província do Maranhão, na cidade de São Luiz e dois anos posteriores, na província do Piauí, na cidade de Oeiras (ALMEIDA, 1989 apud SILVA, 2012). A partir desses dados é necessário levantar pelo menos um questionamento, o que estava ocorrendo naquele momento, seja no centro ou na periferia do poder, para que todas estas 
províncias atentassem para a criação de cadeiras isoladas dessa disciplina?

Segundo Silva (2012) a partir do ano de 1831, para que o aluno ingressasse no Curso Jurídico de São Paulo e Olinda os exames exigiam habilitação em Geografia, além de outras disciplinas. Este pode ser um caminho, já trilhado por Vania Vlach (2004) quando advoga que a origem da disciplina também tem relação com os cursos preparatórios para ingresso no ensino superior. Além da exigência da habilitação em Geografia, não podemos esquecer, que naquele momento haviam debates profundos sobre a constituição do Império e conflitos significativos entre o centro e as províncias e, entre liberais e conservadores, constituindo um jogo que vinha resultando em transformações significativas do ponto de vista do poder e com consequência para a educação.

A implantação do Ato Adicional de 1834 implementa uma descentralização, segundo Haidar (2008) uma pseudodescentralização com consequência para a educação. Em algumas províncias nordestinas, apesar da falta de condições financeiras para projetos educacionais, foram criadas escolas secundárias antes mesmo da fundação do Colégio Pedro II. É nesse interim que foram fundados o Ateneu, no Rio Grande do Norte, em 1835; O Lyceu Provincial da Parahyba e o Liceu da Bahia, em 1836. Segundo a mesma autora, esses Liceus funcionavam sem uma organização serial das disciplinas, se configurando como uma reunião de Cadeiras Isoladas. Assim, em documentação consultada por Pinheiro (2008) é possível observar que o primeiro currículo desta escola na Paraíba era composto pelas seguintes disciplinas: Latim, Francês, Filosofia e Retórica e que nesta última, eram ensinados conteúdos de Geografia, Cronologia, História e Poética. Ainda segundo o mesmo autor, no ano de 1838 , como resultado de embates sobre a organização do estabelecimento foram criadas mais duas cadeiras específicas, a de Inglês e outra de Geografia, Cro- nologia e História, saindo esses conteúdos da cadeira de retórica².

Com a constatação de que os conteúdos de Geografia eram já estudados pelos paraibanos, assim como alunos de outras províncias do Nordeste, desde o ano de 1831, com a criação da cadeira isolada de Geografia, outra questão se evidencia, quais eram os interesses dessa classe dominante e ou dos intelectuais nordestinos para estabelecer tal disciplina em suas escolas secundária províncias? Podemos afirmar que havia uma relação direta entre a data de criação da cadeira e a exigência dessa disciplina nos exames, tendo em vista o interesse da classe dominante paraibana em ver o nome de seus filhos na lista de aprovados para o ingresso nos ensino superior. A necessidade de criação da referida cadeira advém da necessidade de se aprender conteúdos necessários ao ingresso no ensino superior.

É sabido que grande parte dos filhos da classe dominante nordestina estudava em suas residências, com preceptores que os acompanhavam até a idade de poderem sair de casa e continuar seus estudos nas capitais das províncias, em especial naquelas onde os cursos superiores de Medicina, Direito ou mesmo a carreira Militar eram oferecidos, pois somente ai os alunos poderiam fazer os exames para ingresso no ensino superior. Os seus estudos secundários, tanto com os preceptores quanto nas escolas de suas províncias, não eram certificados, pelo menos em um primeiro momento, o que lhes exigia uma certificação.

Tal certificação para o ingresso no ensino superior era feito inicialmente a partir dos exames realizados por professores peritos naquela matéria e que fossem professores dos Cursos Jurídicos ou de Medicina. Com a fundação do Colégio Pedro II, os alunos que concluíssem os sete anos de escolaridade nesta instituição, receberiam o título de Bacharel e poderiam

2 Como se pode observar destacamos os documentos referentes à Paraíba, por ser esta província a que temos nos dedicado mais especificamente em nossas pesquisas e que temos acesso aos documentos de época. 
ingressar nos cursos superiores sem a necessidade de prestar tais exames. Entretanto, para os alunos que não faziam parte deste seleto número de estudantes os exames continuaram sendo obrigatórios. Vale ressaltar que mesmo parte dos alunos do Colégio Pedro II, também se valiam desses exames, pois caso fossem aprovados, abandonavam os estudos no referido Colégio e ingressariam mais rapidamente no ensino superior. Esta era uma prática recorrente, tendo em vista que era pequeno o número de alunos finalizavam seus estudos naquela instituição.

Com isto os alunos que estudavam nos liceus provinciais, nas escolas privadas ou ainda nos cursos preparatórios, oferecidos pelas instituições de ensino superior, tinham que se deslocar para realizar tais exames nas cidades onde eles eram ofertados.

Segundo Haidar (2008) esses exames foram sendo modificados ao longo do século XIX, devido a denúncias de favorecimento de alunos; do desleixo dos professores nos cursos preparatórios; das acusações de os professores desses cursos não cumprirem com suas obrigações, entretanto, oferecerem aulas particulares com os mesmos objetivos de formar alunos para ingressarem nos tais exames, além de outros problemas, com a pouca seriedade desses exames.

Haidar (2008) ainda ressalta o fato de que esses exames terminavam funcionando como "currículos" que orientavam a estrutura do ensino secundário, entretanto, esse não seguia uma estrutura regular, seriada e não tinha articulação com o ensino primário, ou seja, não funcionava como uma continuidade. 0 ensino secundário funcionava como uma preparação para o ingresso no ensino superior, ou seja, como uma passagem. Acrescenta ainda Gondra; Schueler:

"Colégios, liceus, aulas isoladas e cursos de preparatórios tinham prestígios sociais diversos e visavam a objetivos pedagógicos diferentes, distinguindo-se nitidamente em suas organizações didáticas, na preparação e nas condições de trabalho de seus professores". (2008, p. 126).
Desse modo se pode compreender que tais instituições apresentavam currículos distintos tendo em vista que se prestavam a projetos e a objetivos diferentes, o que nos possibilita afirmar que é necessário conhecer tais currículos para melhor compreendermos as diferentes geografias trabalhadas nessas instituições.

Diante deste apanhado de informações, podemos inferir que a cadeira isolada de Geografia que criada na Paraíba, assim como aquelas criadas nas demais províncias do Nordeste, exatamente no mesmo ano de 1831, em que esta disciplina passa a compor uma das exigências do exame preparatório, ou seja, tem relação com o estabelecimento de um “currículo" a ser cumprido, ou seja, os exames. Desse modo, podemos mesmo advogar que as exigências estabelecidas a nível nacional não eram desprezadas pela intelectualidade ou mesmo pela elite econômica da Paraíba e de outras províncias nordestinas.

É nesta perspectiva que compreendemos que uma Geografia era ensinada nestas instituições e provavelmente tinha como norteador curricular os conteúdos estabelecidos para os tais exames. Entretanto, até agora não encontramos uma documentação que comprove exatamente esse currículo, a seleção de conteúdos e os compêndios adotados. Entretanto é possível afirmar que essa Geografia, exigida para os exames, era mais comum aos estudantes do ensino secundário brasileiro do que aquela lecionada no Colégio Pedro II, tendo em vista que neste estabelecimento o número de alunos matriculados não era maior do que o número de alunos matriculados em todos os liceus, escolas privadas e escolas avulsas existentes no país. Outro fato é que o Colégio Pedro II, diferentemente das outras formas de escola existentes, não tinha como objetivo somente a passagem para o ensino superior, visto que aquele curso formava Bacharéis e não somente estudantes secundaristas.

Outra questão ainda deve ser ressaltada, é necessário compreender melhor o alcance do poder do Colégio Pedro II e entender que esse poder não se dissipa 
efetivamente pelo país uniformemente, pois o fazer pedagógico, mesmo hoje, não cumpre efetivamente o que se estabelece em lei, imagina naquele momento quando a demora para a efetivação de uma normatização era muito maior. Por isto, é necessário conhecer como a Geografia escolar se estabeleceu e verificar o que estamos denominando Geografia escolar.

Tendo em vista esta perspectiva é que afirmamos a necessidade de conhecermos melhor a Geografia que era lecionada nas escolas secundárias e compará-la aquela estabelecida para o Colégio Pedro II. Somente com esta análise é que se poderá indicar efetivamente qual era a Geografia escolar mais divulgada no país, aquela que realmente chegava a maioria dos alunos do Império, para não incorrermos no risco de aceitar a data de institucionalização dessa disciplina naquela instituição, como a data de origem dessa disciplina, pois como vimos a Geografia escolar é anterior à fundação do Colégio Pedro II.

0 que se coloca agora como desafio é fazer um trabalho que demanda a organização de uma equipe interinstitucional que possibilite o contato com fontes que se encontram em lugares diferentes, assim teremos que ampliar a área de abrangência da pesquisa para empreendermos uma análise comparativa. Essa análise poderá nos mostrar apontamentos importantes, visto que essas escolas secundárias tinham objetivos distintos. Chervel (1990) aponta exatamente para esta questão, ou seja, uma disciplina passa por transformações de acordo com os seus objetivos em um determinado período.
Como conhecemos o currículo do Pedro II, que está bem documentado e temos acesso a ele na obra de Venchia e Lorenz (1998) nos falta efetivamente encontrar os currículos detalhados que eram adotados nos liceus, escolas privadas e cursos preparatórios, muitos deles fundados antes mesmo do Pedro II. Outra análise ainda precisa também ser feita é descobrir efetivamente se 0 Colégio Pedro II tinha alguma influência nos currículos das escolas localizadas nas províncias e se teve, a partir de quando isto passou a ocorrer. Pois grande parte da literatura sobre esta escola tende a mostrá-la como modelo. Daí sim, podermos verificar que tipo de influência ela tinha sobre as demais escolas do Império.

Este é um dos intuitos pelo qual estamos hoje nos mobilizando para formar uma rede de pesquisadores de Geografia escolar do Nordeste, de forma que possamos trabalhar em uma perspectiva regional, com uma articulação mais ampla do que aquela estabelecida para cada um em seus estados isoladamente.

Nesta perspectiva teremos que trabalhar com fontes primárias, tendo em vista necessitarmos de documentação para compreender melhor esta geografia difundida, especialmente logo após a independência. As fontes secundárias poderão nos encaminhar na busca de tais documentos tendo em vista que existe hoje no Nordeste um número significativo de grupos de pesquisa que trabaIham com História da Educação e que podem nos oferecer caminhos para as nossas buscas. Acreditamos que será necessário nos articularmos com tais grupos para conseguirmos compreender o percurso dessa disciplina escolar.

\section{CONSIDERAÇÕES FINAIS}

Os questionamentos que apresentamos sobre a origem da disciplina escolar Geografia e a proposição de constituição de uma rede de pesquisadores para trabalhar com a Geografia escolar no Nordeste são frutos de debates que realizamos nos últimos anos junto ao GPCES, na UFPB e que tem contribuído de forma sistemática com um trabalho de organização de acervo que tem possibilitado a pesquisadores de diferentes lugares realizarem seus trabalhos. 
A necessidade dessa rede vem se configurando desde algum tempo, quando passamos a observar a dificuldade em encontrar documentos referentes a uma província quando nos estabelecemos em outra. Pois, as fontes históricas referentes ao centro do poder, especialmente no Centro Sul do país, tiveram seus destinos melhor organizados, se encontram em museus, em grandes bibliotecas, em instituições que tem como propósito a guarda e divulgação desses. Entretanto, nas províncias do Nordeste esse mesmo procedimento nem sempre ocorreu, de forma que a documentação, especialmente a escolar foi, muitas vezes, jogada fora ou se encontra em instituições sem condições de guarda. Em outros casos essas instituições até apresentam condições de guarda, entretanto, tais documentos ainda não foram digitalizados e somente podem ser consultados in loco, o que nos obrigaria a um trabalho imenso de catalogação em cada uma dessas instituições em todos os estados do Nordeste.

Como pretendemos realizar uma pesquisa comparativa entre os currículos dos liceus, escola privadas e cursos preparatórios e aquele estabelecido para o Colégio Pedro II, necessitaremos incialmente fazer um grande levantamento nas províncias para encontrar referências aos currículos dessas escolas para em seguida fazer a comparação. Entretanto, conhecemos as dificuldades para desco- brir tais currículos, tendo em vista que se há dificuldades para encontrar os documentos de Liceus, que são instituições públicas e que existem até os dias atuais, imagina aqueles referentes a outros tipos de instituições que não existem mais, e outras que devem ter tido existência efêmera, entretanto, se procurarmos na região como um todo, será possível encontrar em escolas privadas mais antigas, em escolas públicas que guardaram documentação, assim como em instituições destinadas a este fim. 0 certo é que a busca feita por um grupo de pesquisadores terá maiores possibilidade de sucesso do que o trabalho realizado somente por um pesquisador junto com seus orientandos em um único estado da federação.

É com o objetivo de discutir a pesquisa sobre Geografia escolar no Nordeste e constituir essa rede de pesquisadores que estamos organizando na UFPB, em conjunto com a Universidade Federa de Campina Grande - UFCG e a Universidade Estadual da Paraíba - UEPB o Encontro Regional de Prática de Ensino de Geografia - EREPEG, que será realizado em João Pessoa, no ano de 2011. É a partir da constituição dessa rede que daremos início a pesquisa que tanto nos estimula neste momento, ou seja, conhecer a contribuição das províncias nordestina na constituição da Geografia escola brasileira. 


\section{REFERENCIAS}

ALBUQUERQUE, Maria Adailza Martins de. Ensino de Geografia: As imagens nos livros didáticos de Geografia: uma perspectiva histórica. In. VASCONCELOS. José Gerardo et al (Orgs.). Tempo, Espaço e Memória da Educação. Fortaleza: Edições UFC, 2010.

AlBuQUERQUE, Maria Adailza Martins de. Século de prática de ensino de Geografia. In. REGO, Nelson; CASTROGIOVANI, A. Carlos; KAERCHER, Nestor (Orgs.). Geografia: práticas pedagógicas para o ensino médio - Vol. 2. Porto Alegre: Penso, 2011.

ALBUQUERQUE, Maria Adailza Martins de. Dois momentos na história da Geografia escolar: a Geografia clássica e as contribuições de Delgado de Carvalho. In. Revista Brasileira de Educação em Geografia. Vol. 1, n², 2011a. P. 19 a 51.

BRASIL. Coleção de Leis do Império do Brasil - 1831, p. 8 Vol. 1. In. <http://www.camara.gov.br/Internet/ InfDoc/conteudo/colecoes/Legislacao/Legimp-14/ Legimp-14_5.pdf>. Acesso: 14. Agos. 2012.

CHERVEL, André. História das disciplinas escolares: reflexões sobre um campo de pesquisa. Teoria e Educação, Porto Alegre, nº. 02, p. 177-229, 1990.

GOODSON, Ivor F. Tornando-se uma matéria acadêmica: padrões de explicação e evolução. In: Revista Teoria e Educação, nº 2. 1990. p. 231 - 255.

GONDRA, José Gonçalves; SCHUELER, Alessandra. Educação, poder e sociedade no Império brasileiro. São Paulo: Cortez, 2008.
HAIDAR, Maria de Lourdes Mariotto. O Ensino Secundário no Brasil Império. São Paulo: EDUSP, 2008.

PINHEIRO, Antônio Carlos Ferreira. Da Era das Cadeiras Isoladas à Era dos Grupos Escolares na Paraíba. São Paulo: Universidade São Francisco, 2002.

PINHEIRO, Antônio Carlos Ferreira. FERRONATO, Cristiano A institucionalização da Instrução púbica e particular na província da Parahyba do Norte (1821 1840). In. Temas sobre a instrução no Brasil imperial (1822 - 1889). João Pessoa: Editora da UFPB, 2008.

ROCHA, Genylton Odilon Rego da. A trajetória da disciplina Geografia no currículo escolar brasileiro (1839 - 1942). Dissertação (Mestrado em Educação e Currículo). São Paulo: PUC/SP, 1996.

SHARPE, Jim. A história vista de baixo. In. BURKE, Peter. (Org.). A escrita da História - novas perspectivas. São Paulo: Editora da UNESP, 1992.

SILVA, Jeane Medeiros. A bibliografia didática de Geografia: história e pensamento do ensino geográfico no Brasil (1814 - 1930). Tese (Doutorado Instituto de Geografia). Uberlândia: Universidade Federal de Uberlândia, 2012.

VECHIA, Ariclê; LORENZ, Karl Michael (Org.). Programa de ensino das escolas secundárias brasileiras 1850 - 1951. Curitiba: Ed. do autor, 1998.

VLACHE, Vania Rubia de Farias. 0 ensino de Geografia no Brasil: uma perspectiva histórica. |In: VESENTINI, José William (Org.). 0 ensino de Geografia no século XXI. Campinas: Papirus, 2004. 
$\cdot 23$.

1 Doutora e professora da Universidade Federal da Paraíba. Email: dadamartins@ig.com.br 